
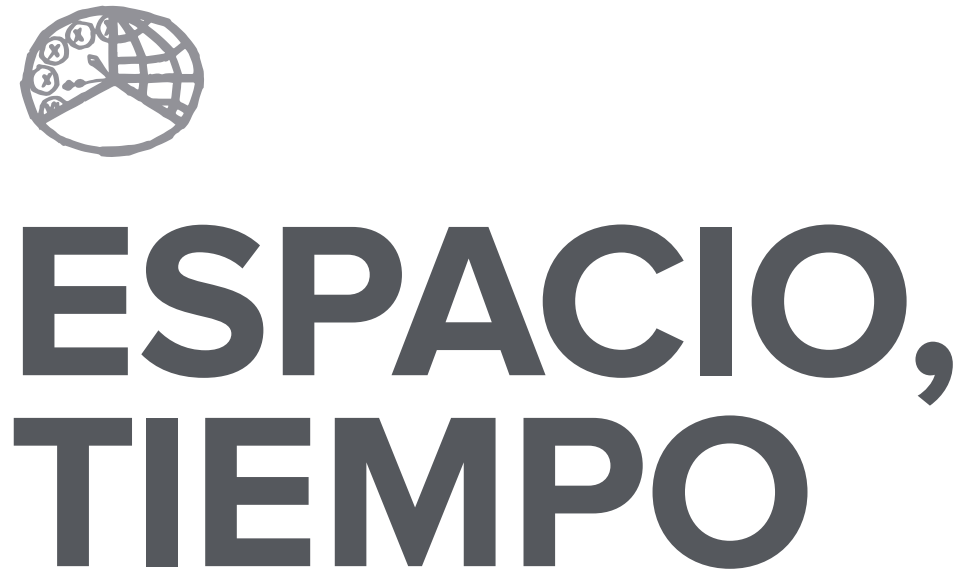

AÑO 2016

ISSN 0214-9745

E-ISSN 2340-1362
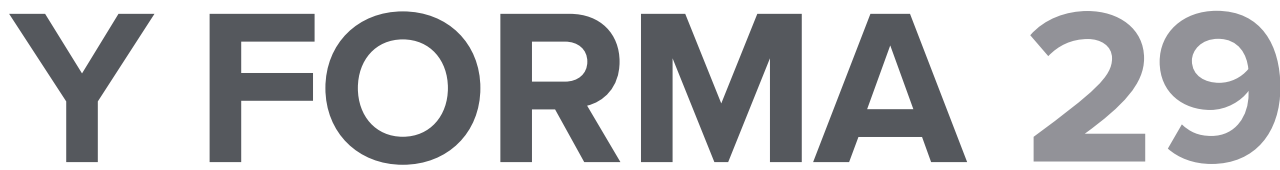

SERIE III HISTORIA MEDIEVAL

REVISTA DE LA FACULTAD DE GEOGRAFÍA E HISTORIA 


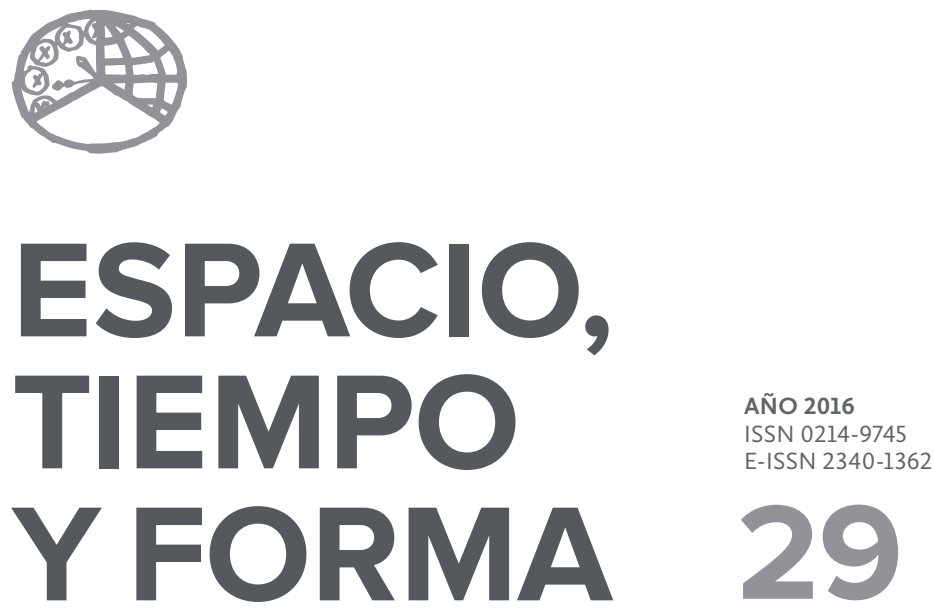

SERIE III HISTORIA MEDIEVAL

REVISTA DE LA FACULTAD DE GEOGRAFÍA E HISTORIA

http://dx.doi.org/10.5944/etfiii.29.2016

\section{UกED}

UNIVERSIDAD NACIONAL DE EDUCACIÓN A DISTANCIA 
La revista Espacio, Tiempo y Forma (siglas recomendadas: ETF),

de la Facultad de Geografía e Historia de la UNED, que inició su publicación el año 1988, está organizada de la siguiente forma:

$$
\begin{aligned}
& \text { SERIE I - Prehistoria y Arqueología } \\
& \text { SERIE II - Historia Antigua } \\
& \text { SERIE III - Historia Medieval } \\
& \text { SERIE IV - Historia Moderna } \\
& \text { SERIE V - Historia Contemporánea } \\
& \text { SERIE VI - Geografía } \\
& \text { SERIE VII - Historia del Arte }
\end{aligned}
$$

Excepcionalmente, algunos volúmenes del año 1988 atienden a la siguiente numeración:
N. ${ }^{\circ} 1$ - Historia Contemporánea
N. ${ }^{\circ} 2-$ Historia del Arte
N. ${ }^{\circ} 3-$ Geografía
N. ${ }^{\circ} 4 \quad-$ Historia Moderna

ETF no se solidariza necesariamente con las opiniones expresadas por los autores.

UNIVERSIDAD NACIONAL DE EDUCACIÓN A DISTANCIA

Madrid, 2016

SERIE III - HISTORIA MEDIEVAL N. ${ }^{\circ} 29,2016$

ISSN 0214-9745 · E-ISSN 2340-1362

DEPÓSITO LEGAL M-21037-1988

URL: ETF III - HISTORIA MEDIEVAL · http://revistas.uned.es/index.php/ETFIII

DISEÑO Y COMPOSICIÓN

Carmen Chincoa Gallardo · http://www.laurisilva.net/cch

Impreso en España · Printed in Spain 


\section{ARTÍCULOS}





\title{
LA COPIA DE ESCRITURAS PÚBLICAS A LA MUERTE DEL NOTARIO TITULAR ${ }^{1}$
}

\section{ISSUING PUBLIC DOCUMENTS AFTER THE DEATH OF A PUBLIC NOTARY}

\author{
Roberto Antuña Castro² \\ Recepción: 2015/10/22 . Comunicación de observaciones de evaluadores: 2015/12/10 . \\ Aceptación: 2016/1/25 \\ DOI: http://dx.doi.org/10.5944/etfiii.29.2016.15467
}

\section{Resumen}

Este trabajo estudia el proceso observado en la extensión de aquellos instrumentos públicos que no han llegado a formalizarse ni, por tanto, a entregarse a las partes, por la muerte del notario titular que había estado presente a su otorgamiento y que había recogido en su libro registro. Aunque en la legislación alfonsina se establece de manera contradictoria cómo se debía actuar, la práctica nos muestra cómo se hace necesaria la intervención judicial para que esas escrituras se expidiesen con todo su valor legal. Para ello, el interesado acude a la autoridad judicial para que dé su licencia al oficial sucesor en la notaría para confeccionar la carta, previa comprobación de la autenticidad de las notas encontradas en el registro que ha dejado el escribano finado. Gracias a este estudio realizamos una aportación sobre una realidad que en parte nos era desconocida: el procedimiento seguido para valerse del registro de un notario fallecido y redactar una escritura definitiva y completa a partir de él.

\section{Palabras clave}

Diplomática notarial; notariado bajomedieval; registro notarial; escribano público del número de Toledo; Luis Díaz de Toledo; censo enfitéutico.

1. Trabajo realizado en el marco del proyecto de investigación «Escritura, notariado y espacio urbano en la Corona de Castilla y Portugal (siglos XII-XVII)», ref. HAR2015-63676-P. Ministerio de Economía y Competitividad.

2. UNED (C.A. Asturias). C.e.: roberantu@yahoo.es. ORCID ID: orcid.org/0000-0003-0884-7241. 


\begin{abstract}
This study analyzes the process of issuing public documents which have not been certified and, consequently, have not been handed over to the parties concerned as a result of the death of the notary who was present at the time it was submitted and who was responsible for recording it in the register. Even though legislation adopted under Alfonso X made these norms confusing, in practice we can observe how judicial intervention was necessary in order for these notarial deeds to be legally binding. It was essential for the individual concerned to turn to the judicial authorities who could grant a licence to the successor of the notary in order to prepare a deed having previously checked the authenticity of the draft found in the deceased notary's register. This study provides insight into an issue that was previously ill-known, namely the procedure undertaken to produce a formal and definitive deed based on the register of a deceased notary.
\end{abstract}

Keywords

Notarial Diplomatics; Notaries in the Late Middle Ages; Notary Register; Toledo Public Notary; Luis Díaz de Toledo; Emphyteutic Census. 


\section{INTRODUCCIÓN}

Luis Díaz de Toledo verá frustrada su pretensión de obtener un instrumento público de un negocio en el que participó, pues a pesar de haberle requerido al notario Alfonso González de Segovia su escrituración en diversas ocasiones, no lo logrará debido al fallecimiento del dicho escribano público. Ante esta adversidad, nuestro protagonista se ve obligado a acudir a la autoridad judicial para conseguir su carta. Lo hará mediante un procurador que actuará en su nombre. Gracias a ello presentamos una interesante escritura en cuanto en ella se muestra el proceso por el cual se expide una carta a partir de las notas del libro registro de un notario público fallecido³, quien nunca llevará a cabo el documento definitivo y completo, con lo que el iter documental no aparece concluso al paralizarse en el registro, sin llegar a realizarse la confectio. Por ello, la parte interesada en conseguir el documento bajo forma pública acude a la autoridad judicial (en este caso, el alcalde de Toledo) para que sea ésta quien constate la autenticidad de las notas del difunto notario y, una vez comprobado, ordene al sucesor en la escribanía expedir sendos instrumentos, los cuales serán debidamente autorizados por el alcalde mediante su firma, junto a la suscripción y el signo notarial del expedidor de las escrituras. Se trata, por lo tanto, de una aportación al conocimiento sobre una realidad que en parte se nos escapaba, como es la utilización del registro de un notario fallecido y el procedimiento que se sigue para confeccionar una escritura pública a partir de él.

El documento en cuestión, sacado del libro registro, es una carta de constitución de censo del tipo enfitéutico, siendo así como se denomina en la propia escritura (carta de çenso ynfitheosy) ${ }^{4}$. En este tipo de contratos se transfiere la posesión y disfrute de un bien inmueble, es decir, el dominio útil, mientras que se reserva el dominio directo al dueño de dicho bien, a cambio de recibir una pensión anual en reconocimiento de ese dominio directo ${ }^{5}$. Son dados en censo unas casas situadas en la collación de la iglesia de Santo Tomé de Toledo, siendo su propietario el hijo primogénito del doctor Fernán Díaz de Toledo, persona que había acumulado diversos oficios y cargos en la Corte, entre ellos llegó a ser miembro del Consejo Real, referendario, relator, secretario y notario mayor de los privilegios rodados...6;

3. AHN, Sección Clero regular, Convento de Santo Domingo el Real de Toledo, c. 3090, $n^{\circ}$ 16. Juan Jiménez, como procurador del relator Luis Díaz de Toledo, solicita a Gonzalo de la Fuente, alcalde de Toledo, diese licencia al escribano público del número Alfonso González de Valladolid para que sacase de las minutas del registro de Alfonso González de Segovia, escribano público difunto, una carta de constitución de censo enfitéutico que no se habría llegado a extender. Se incluye dicha carta de censo. Fechada en Toledo el 16 de noviembre de 1457.

4. José BONO HUERTA define enfiteusis «A entrega (propiamente transfiere) el dominio útil de una o varias fincas a $B$, transmisible por herencia, y enajenable, por un canon anuo perpetuo» en Los archivos notariales, Sevilla: Junta de Andalucía. Dirección General del Libro, Bibliotecas y Archivos, 1985, p. 36.

5. Moreno TrujIllo, María Amparo: «El documento de censo en la Castilla del siglo XVI», Revista de Derecho Notarial, CXLV-CXLVI (julio-diciembre, 1989), p. 318.

6. Una pequeña biografía de Fernando Díaz de Toledo la encontramos en CAÑAS GÁlvez, Francisco de Paula: 
quien, en palabras de la profesora Sanz Fuentes, tal vez fuera «el hombre más poderoso de la corte de Juan II», sin duda por la cercanía que tendría con el rey y la influencia que mantendría sobre éste ${ }^{7}$. Fernán Díaz además es el autor del formulario conocido como Las notas del Relator, el cual estaba destinado para que fuera utilizado por los notarios públicos ${ }^{8}$.

El citado Luis Díaz de Toledo, al igual que su padre, acumulará oficios y mercedes en su persona ${ }^{9}$, siendo ésta una manera para enriquecerse y ascender en el escalafón social, puesto que de este modo nuestro protagonista consigue acceder a las rentas de la hacienda real ${ }^{\mathrm{ro}}$. No obstante, debemos advertir que alguno de los cargos que obtendrá no tendrían ninguna retribución económica al ser sólo de carácter honorífico, como puede ser el de Consejero, ya que éste en concreto lo

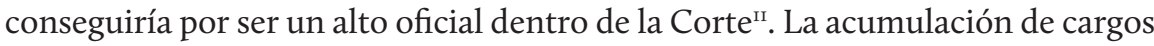
supone unas mayores fuentes de ingresos, pero también es muestra del interés de los reyes para que ciertas personas de su mayor confianza pudieran actuar con diversas funciones políticas, jurídicas... ${ }^{\text {I2 }}$

\section{CUÁNDO DEBÍA ENTREGAR EL NOTARIO LA ESCRITURA PÚBLICA}

Entre la nota del registro y la expedición del instrumento público definitivo, tras la intervención del alcalde, transcurre un lapso temporal de algo más de tres años sin conseguir que el notario confeccionara la carta. Aunque desconocemos la fecha exacta del óbito del notario, se advierte su dejadez a la hora de autorizar el documento original y definitivo por motivos que también se nos escapan. En vida del escribano público es él el único capacitado para extender un documento a partir de la nota de su registro, salvo en casos excepcionales, como puede ser enfermedad, momento en que se podía acudir a otro notario.

Según se recoge en la propia escritura, Luis Díaz de Toledo le pide insistentemente la entrega del instrumento público, pero nunca se llegará redactar.

\footnotetext{
Burocracia y cancillería en la corte de Juan II de Castilla (1406-1454). Estudio institucional y prosopográfico, Salamanca: Ediciones Universidad de Salamanca, 2012, pp. 297-301.

7. Sanz Fuentes, María Josefa: «El testamento de Fernán Díaz de Toledo, el Relator (1455)», Historia. Instituciones. Documentos, 41 (2014), pp. 381-382.

8. En este libro localizamos un modelo de carta para censo (ff. 13 v.-15 v.), pero no se corresponde con el utilizado en nuestra escritura.

9. Se recogen todos ellos en CAÑAS GÁLVEZ, Francisco de Paula: op. cit., pp. 301-302. En esta misma obra se estudia el proceso de acumulación de oficios por parte de su padre Fernando Díaz de Toledo, pássim.

10. Dıos, Salustiano de: El Consejo Real de Castilla (1385-1522), Madrid: Centro de Estudios Constitucionales, 1982 , p. 294.

11. Dios, Salustiano de: ídem, pp. 258-259.

12. Bermejo Cabrero, José Luis: «Los primeros secretarios de los reyes», Anuario de Historia del Derecho Español, 49 (1979), $n^{\circ} 4$, p. 229.
} 
El qual dicho Alfonso Gonçález de Segovia, escrivano, diz que en su vida non le dio nin entregó el contrabto del dicho çenso que al dicho Luys Díaz, e a él en su nonbre, pertenençía, non enbargante que por muchas de vezes ge lo pidió.

Consideramos que la muerte del escribano se tendría que haber producido entre el ig de mayo de I457, fecha en que Enrique IV confirma a Luis Díaz de Toledo el cargo de relator, título con el que es citado en el documento, y antes del i6 de noviembre del mismo año, que es cuando se eleva la petición para obtener la escritura pública. La razón para que lo encuadremos dentro de ese arco cronológico, como veremos en detalle más adelante, se debe a las notas marginales que acompañan a cada uno de los asientos y que, según los testigos, estarían realizadas por el propio notario público fallecido, pues en ellas se expresa uno de los oficios que Luis Díaz hereda de su padre tras su defunción: el de relator.

En la Partida 3.19.9 hallamos las obligaciones de los escribanos públicos ${ }^{13}$. Entre ellas, los notarios debían realizar la escritura con los datos consignados en el registro y entregársela al interesado, pero sin indicar cuándo tenían que hacerlo. Más explícito era el Fuero Real I.8.3 en cuanto al plazo de entrega del instrumento público, aunque no se especifica un límite temporal concreto, pero si señala que no se podía retrasar. En esta ley se recoge que el escribano público ante la demanda de escrituración que la faga sin otro alongamiento ninguno, añadiendo además que non la deje de facer por amor, nin por desamor, nin por miedo, nin por verguenza de home ninguno. En fin, que ante el requerimiento al notario de sus servicios éste debía redactar la carta sin dilación, puesto que entraría dentro del deber de asistencia que iba aparejado al oficio notarial ${ }^{14}$. En este mismo sentido, aunque posteriormente, observamos que en las Ordenanzas de los escribanos públicos de Córdoba de 1533 se establece «que después de tener la escritura en registro no dilatarán darla en claro a las partes a quien pertenece maliciosamente» ${ }^{15}$.

\section{LEGISLACIÓN SOBRE LOS ESCRIBANOS PÚBLICOS FALLECIDOS Y SUS REGISTROS}

Por una u otra razón el notario no escritura el negocio, llegando a morir sin hacerlo. Por eso, en lo que a nosotros nos respecta, en la Partida 3.I8.55 se regula

13. que deben haber un libro por registro en que escriban las notas de todas las cartas (...); et despues desto deben facer las cartas guardando la forma de cada una dellas segunt desuso es dicho en el título de las escripturas, non mudando nin camiando ninguna cosa de la sustancia del fecho, asi como en el registro fuere puesto; et desi hanla de dar a aquel que la ha de haber.

14. Bono HuertA, José: Historia del Derecho notarial español, I.2, Madrid: Junta de Decanos de los Colegios Notariales de España, 1982, p. 318.

15. BOnO Huerta, José: ídem, p. 251. 
cómo se debía actuar en estos casos en que el escribano público no ha podido (o querido) realizar la expedición de la escritura pública antes de su muerte. Sin embargo, lo aquí preceptuado difiere con la práctica que se vislumbra en nuestro documento, pues en él se requiere a la autoridad judicial para expedir la escritura definitiva, mientras que en esta ley de las Partidas no se expresa tal cosa: el nuevo notario tras jurar que guardará los registros del fallecido y que sacará fielmente a partir de ellos los instrumentos públicos pendientes cuando le fuera reclamado, ya podría confeccionar esos instrumentos definitivos por sí mismo, sin necesidad de contar con ninguna licencia judicial, siendo suficiente para ello la petición de los interesados.

Por contra, en Fuero Real I.8.4 sí se expresa que una vez realizada la nota, si el escribano público muere antes de autorizar la carta pública ${ }^{16}$ :

\section{el alcalle mande facer a otro escribano la carta por aquella nota misma si alguna de las partes la demandare, e vala asi como si el escribano que la notó la oviese fecha.}

Es decir, que según el Fuero Real se redactaría la escritura pública bajo mandato judicial. En este mismo sentido se pronuncia el Fuero de Soria, pues en el título dedicado a los escribanos públicos, en su ley 75 se regula que ${ }^{17}$ :

Si escriuano publico fiziere nota por fazer carta sobre algun pleyto, e ante que la carta aya fecha muriere o el conçeio lo echare del ofiçio, el conçeio ponga otro en su lugar e den le todos los registros que tenia aquel escriuano que perdió el ofiçio, e los alcalldes manden gela fazer aquel escriuano que el conçeio puso de nueuo e el faga la por aquella nota misma ala parte que deuiere auer; e uala, assi commo si el escriuano que la nota fizo gela ouiesse fecha.

De nuevo la confectio de la carta se realiza bajo decreto judicial. En este punto debemos aclarar que, debido a las similitudes de contenido, se creía que el Fuero de Soria había servido de fuente al Fuero Real, pues se le suponía concedido por Alfonso VIII. Sin embargo, Gonzalo Martínez Díaz apuntará a que el Fuero de Soria recibió la influencia del Fuero Real, y no al revés ${ }^{18}$.

Ante esta contrariedad legislativa sobre la necesidad o no de la intervención judicial ${ }^{19}$, la práctica indica que el interesado en conseguir la escritura pública se dirige a la autoridad judicial para que mandase al notario sucesor la confección del instrumento. Esta actuación del alcalde se deja sentir desde el comienzo y

16. Para conocer la influencia del Fuero Real en variados aspectos en las villas de titularidad señorial es conveniente revisar: LóPEZ VILLALBA, José Miguel: «Ordenanzas señoriales y vida cotidiana en el comienzo de la Edad Moderna segoviana», Studia Historica. Historia Medieval, 32 (2014), pp. 239-270.

17. SÁnCHEZ, Galo: Fueros castellanos de Soria y Alcalá de Henares, Madrid, 1919, p. 31.

18. Martínez Díez, Gonzalo: «El Fuero Real y el Fuero de Soria», Anuario de Historia del Derecho Español, 39 (1969), pp. 545-562.

19. En lo que se pone de acuerdo la legislación es que la escritura pública confeccionada a partir de la nota del notario fallecido tendría el mismo valor que si la hubiera hecho el mismo. 
cerrará el documento junto a la suscripción y signo notarial. Según hemos visto en la Partida 3.I8.55, la actuación de los alcaldes quedaría limitada a mandar a homes bonos a la casa del notario muerto para requisar todas las notas y registros que encontraren en su despacho, los cuales serán sellados y custodiados en lugar seguro, para evitar su deterioro o posibles manipulaciones, hasta su entrega al nuevo escribano público sucesor en el cargo.

Debemos tener claro que no se trata de un traslado notarial con intervención de la autoridad judicial, puesto que la escritura original no la llegó a extender el escribano público ante quien se otorgó. No obstante, parece que se prefiere la intervención del alcalde, puesto que los traslados notariales en los que participa será su actuación, ordenando la escrituración del instrumento público, la que le dé fuerza legal. Sabemos que los traslados autorizados únicamente por el notario tenían que ser acompañados por los originales en los procesos judiciales ${ }^{20}$, ya que los documentos notariales originales tienen pleno valor, pero su traslado no, al ser considerados como imperfectos o que su credibilidad no es total, por lo que necesitan de la acción judicial para alcanzarlos ${ }^{21}$. De todas formas, los traslados notariales, aún sin la misma fuerza que el original por la falta de la autoridad judicial, tendrán validez en los negocios privados entre partes ${ }^{22}$.

Otro elemento que choca la práctica con lo dispuesto en la ley 3.I8.55 de las Partidas es que los testigos tampoco intervendrán gráficamente en la escritura, como tampoco lo habrían hecho en el registro. En la ley de la Partida se establecía que si los testigos de la nota estaban vivos, estos debían escribir por sí mismos sus nombres en el instrumento público confeccionado con el notario sucesor. En nuestro caso, los nombres de los testigos de las minutas son los mismos que se encuentran en la carta de censo, pero escritos por el propio notario. Entre estos testigos hay un escribano de cámara, por lo que se le ha de suponer una persona experta en el arte de la escritura, de manera que no se pueda alegar el analfabetismo como razón para no participar de puño y letra. De todas formas, debemos entender que son los testigos del otorgamiento del negocio ante el escribano público, pero que no estaban presentes en la expedición de la carta.

Por otra parte, la práctica nos muestra como no existe ninguna duda en cuanto a que a la transmisión de la escribanía se le sumaba la de los registros de su antecesor. Situación que también se encuentra recogida en la ley i.8.2 del Fuero Real, en que se mandaba que cuando el notario muere, los alcaldes debían de recoger los registros de dicho notario y entregarlos a su sucesor en el oficio.

\footnotetext{
20. Ostos SALCEDo, Pilar: «Los escribanos públicos y la validación documental», en La validación de los documentos: pasado, presente y futuro: octavas jornadas archivísticas, Huelva: Diputación Provincial de Huelva, 2007, p. 42.

21. BONO HUERTA, José: «Conceptos fundamentales de la Diplomática notarial», Historia. Instituciones. Documentos, 19 (1992), p. 87.

22. BONO HUERTA, José: «Modos textuales de transmisión del documento notarial medieval», Estudis Històrics $i$ Documents dels Arxius de Protocols, XIII (1995), p. 99.
} 


\section{ANÁLISIS DEL DOCUMENTO}

Pasando a analizar el documento notarial, observamos cómo el proceso de expedición es similar al que nos da a conocer la profesora Ostos Salcedo en el estudio que realiza de una renovación documental de principios del siglo XIV, en la que se hace indispensable la actuación del alcalde, junto a la del notario, para autorizar esa escritura renovada ${ }^{23}$. Aunque en este caso se trata de una copia, si bien revestida de las garantías y solemnidades requeridas.

En cuanto a la categoría de la tradición documental de nuestra carta debemos incluirla dentro de exemplatio de notas relictas, es decir, la copia de las notas dejadas por un notario fallecido y que realizará su heredero en el oficio ${ }^{24}$. Es el alcalde quien autoriza, en nuestro caso, al notario sucesor para elevar a pública forma las notas del finado referentes al censo del que es objeto nuestro estudio. La falta de alguno de los elementos de validación que le corresponderían al original (suscripción y signo notarial), son suplidas por la intervención del alcalde y del escribano público sucesor en la notaría (éste último actuando a las órdenes del juez -iussio judicial-), con lo que se eleva las minutas a pública forma. El formato que presenta es el de cuadernillo de pergamino compuesto por dos bifolios escriturados por ambas caras, más una carpetilla, formada en esta ocasión mediante un pliego de papel, que lo individualiza y protege y que se aprovecha también para anotar su contenido, así como las fechas correspondientes a cada una de las partes de las que se compone la escritura, que, como veremos en seguida, está formada por la petición y autorización para la extensión del instrumento público y la propia carta de constitución de censo enfitéutico. El conjunto presenta un buen estado de conservación, aunque la tinta se pierde en ocasiones.

La escritura del documento se corresponde con el tipo gótica cortesana, que siguiendo la clasificación planteada por la profesora Sanz Fuentes se denominaría como escritura gótica cursiva redonda formada ${ }^{25}$.

Para evitar que la escritura pudiera sufrir posibles interpolaciones en el margen inferior de cada uno de los folios se ejecuta una línea horizontal, rematada en cada uno de los extremos por una figura que recuerda vagamente a la clave de sol, y en cuyo centro encontramos la rúbrica del notario; mientras que en el margen superior para cancelar el espacio se aprovecha el signo general de abreviación correspondiente a las palabras abreviadas que se encuentran en el primer renglón de cada folio. Este instrumento público consta de dos partes bien diferenciadas: en la primera se solicita extender la carta de censo enfitéutico a partir del registro

23. Ostos Salcedo, Pilar: «Una renovación documental sevillana (s. XIV)», Historia. Instituciones. Documentos, 19 (1992), pp. 307-316.

24. BOnO Huerta, José: «Modos textuales de transmisión...», pp. 96-99.

25. Sanz Fuentes, María Josefa: «La escritura gótica documental en la Corona de Castilla», en María Josefa SAnz Fuentes y Miguel CAlleja Puerta (coords.): Las escrituras góticas desde 1250 hasta la imprenta. V Jornadas de la Sociedad Española de Ciencias y Técnicas Historiográficas, Oviedo: Universidad de Oviedo, 2010, p. 121. 
del notario fallecido, detallándose el proceso, dirigido por el alcalde, por el cual primero se confirma la existencia de las notas a las que se refiere, para una vez hecho esto estudiarlas para verificar que efectivamente pertenecen a la notaría del finado. Una vez comprobado, el alcalde dará su licencia al escribano público que sustituye en el oficio al finado para confeccionar el instrumento definitivo y completo a partir de los asientos registrados. Es aquí donde comienza la segunda parte del documento, que se corresponde con la redacción y autorización de la carta de constitución de censo enfitéutico.

La primera parte está redacta de forma objetiva, mientras que la carta de censo lo es de forma subjetiva. Ello motiva que la estructura diplomática varíe de una a otra, puesto que la primera se inicia con la datación, seguida de la comparecencia ante el alcalde, notario y testigos, para luego desarrollarse el contenido del documento, finalizando con una relación de los testigos presentes. En ella, será el notario quien tome el protagonismo al estar redactado en primera persona. Por su parte, el sector redactado de forma subjetiva, sigue el esquema habitual de este tipo, iniciado por la notificación, intitulación, dispositivo... aunque, por razones obvias, faltará la suscripción del notario ante quien se otorgó el negocio. Aquí el escribano público pasa a un segundo plano, siendo redactado desde el punto de vista de los otorgantes. Finalmente, como ya hemos dicho, el documento se cierra con la firma y rúbrica del alcalde, dejando constancia de su actuación, junto a la suscripción y el signo notarial del actual oficial. Aunque todo esto lo veremos con más detalle a continuación.

\section{EL PROCEDIMIENTO PARA OBTENER LA ESCRITURA PÚBLICA}

lohán Ximénez, como procurador de Luis Díaz de Toledo, comparece ante Gonzalo de la Fuente, alcalde de Toledo nombrado por el caballero Diego Romero, quien era a su vez alcalde mayor de dicha ciudad y consejero real ${ }^{26}$, en presencia del escribano público de número Alfonso González de Valladolid, solicitando que se diese licencia a este escribano, como sucesor en el oficio de Alfonso González de Segovia, para que sacase por unas notas del libro de registro de este último un contrato de constitución de censo enfitéutico, pues este notario había fallecido sin llegar a expedir la carta pública ${ }^{27}$. En dicho contrato, Luis Díaz de Toledo

26. Diego Romero compra la alcaldía mayor de Toledo en 1456, pero tan sólo cuatro años después renunciará al oficio en favor de Alvar Gómez de Ciudad Real. Este personaje acaparará otros oficios y cargos, tales como: escribano de la notaría mayor de Toledo, escribano de cámara, secretario y contador de Juan II... CaÑAS GÁlveZ, Francisco de Paula: op. cit., pp. 437-440.

27. Se trataría en realidad de un original múltiple puesto que se entrega una escritura a cada una de las partes. 
transfiere a María Núñez, quien era viuda del escribano del rey Fernán García de Acre, el dominio útil de unas casas por un canon anual de 700 maravedís.

El dueño del dominio directo de las casas es Luis Díaz de Toledo, el cual es presentado en esta parte de la escritura como relator, pero también lo hará en otros lugares como secretario del rey. El primero de los cargos, es decir, el de relator, se asocia a su nombre en la parte que se corresponde a la petición de redactar el instrumento público a partir del libro registro del notario fallecido, mientras que como secretario del rey lo hace en las minutas del registro ${ }^{28}$ y en la propia carta de censo que se expide.

En el testamento otorgado por su padre, Luis Díaz de Toledo recibe una serie de rentas asociadas a diversos oficios, algunas de ellas en Toledo, siendo además el único hijo varón legítimo de Fernán Díaz ${ }^{29}$. Asimismo se constituirá un mayorazgo en su persona ${ }^{30}$. Sin embargo, debemos tener presente que el testamento de Fernán Díaz de Toledo se fecha el i6 de febrero de I455, mientras que el censo se formalizaría el 27 de junio de I454, por lo que Luis Díaz no habría aún heredado ninguno de los cargos que ostentaba su padre, así que en esos momentos tan sólo es secretario del rey. La petición para extender la carta de constitución de censo enfitéutico se realiza el I7 de noviembre de i457; cuando Luis Díaz ya había sido incluso confirmado por Enrique IV en los oficios que habría renunciado su padre en él para después de su muerte ${ }^{3 \mathrm{I}}$, pues éste, el relator Fernán Díaz, fallecerá el 2 de mayo de $1457^{32}$. Por este motivo en nuestro documento se identifica a Luis Díaz de Toledo como relator del rey en su parte inicial.

Pero continuando con la descripción de cómo se produce la expedición de la carta de constitución de censo, la solicitud realizada por el procurador es expresada de la siguiente forma:

Por ende, dixo que pedía e pidió al dicho allcalde que mande e apremie a mí, el dicho Alfonso Gonçález de Valladolid, escrivano que subçedí en el ofiçio de la escrivanía pública del dicho Alfonso Gonçález de Segovia, escrivano, que traya e exiba antél los registros e protocolos que a mí an seydo del dicho Alfonso Gonçález de Segovia, escrivano, e que en alguno dellos se fallaría estar asentada la nota de los dichos contrabtos de çensos; e fallada diese liçençia a mí, el dicho escrivano, que sacase por la dicha nota del dicho registro dos contrabtos de çensos fuertes e firmes segúnd

28. No así en las anotaciones marginales, que acompañan a las minutas, en las que se aluden a él como relator. Esas anotaciones serán por tanto muy posteriores a la escrituración de las minutas en el registro.

29. Sanz Fuentes, María Josefa: «El testamento de Fernán Díaz de Toledo...», p. 386.

30. Sanz Fuentes, María Josefa: ídem, p. 398.

31. En una albalá fechada el 19 de mayo de 1457 Enrique IV confirma al bachiller Luis Díaz de Toledo, que era su secretario y alcalde en la Corte, los diversos oficios que había recibido de su padre Fernán Díaz de Toledo, de los cuales había conseguido autorización de Juan II para hacer renuncia de ellos. Esa renuncia se formaliza con Enrique IV para después de la muerte de Fernán Díaz. Entre los oficios confirmados se encuentra el de relator. Por este documento sabemos que el nivel de formación de Luis Díaz fue el de bachiller, no llegando al de doctor de su padre. Archivo General de Simancas, Quitaciones de Corte, leg. 4, fol. 55 r y v.; Lo edita Bermejo CaBrero, José Luis: op. cit., pp. 267-268.

32. Cañas Gálvez, Francisco de Paula: op. cit., p. 68. 
e en la forma que se acostunbra fazer e los signase con mi signo e el dicho allcalde firmase de su nonbre e ynterpusiese a ellos su attoridad e decreto; e que lo pedía e pidió por testimonio.

Tras la petición al alcalde, éste manda que el notario sucesor le lleve y exhiba ante él los libros de registro del difunto. Alfonso González de Valladolid tendrá los libros de registro de Alfonso González de Segovia por sucederle en el oficio ${ }^{33}$.

\begin{abstract}
E luego, el dicho allcalde dixo que mandava e mandó a mí, el dicho escrivano, que traxiese e exibiese antél algunos de los libros e protocolos del dicho Alfonso Gonçález de Segovia que yo tenía en mi poder e quél los faría catar e buscar; e fallada la nota de los dichos contrabtos quél estava presto de fazer lo que con derecho deva.
\end{abstract}

Al igual que en la Partida 3.I8.55, en el Fuero Real I.8.4 se indica que los alcaldes debían recoger el registro de las notas del escribano fallecido y entregarlas a su sucesor. Por otro lado, en las ordenanzas municipales de Toledo se establece cómo se cubre una vacante en el oficio de escribano público: El nuevo notario sería escogido por miembros del concejo entre las personas que consideran más idónea para el cargo, sin hablar en ningún momento de la necesidad de realizar algún tipo de examen para demostrar sus conocimientos y valía ${ }^{34}$.

Aunque son escasos los libros de registros notariales castellanos conservados anteriores a la mitad del siglo $\mathrm{xv}$, tenemos referencias en los propios documentos notariales de cómo esos registros existían desde la implantación del notariado público $^{35}$. En la Partida 3.I8.II5 se constata la importancia de los libros de registros cuando se pone en duda la autenticidad de una carta confeccionada por escribano público, ya que si en un juicio se expresa que una escritura es falsa, y existiendo contrariedad entre los testigos que se recogen en la escritura, al decir que ellos no estuvieron realmente presentes o que la escritura no es fiel a lo otorgado, mientras que el fedatario afirma que la carta es verdadera, se recurre al libro registro, pues si se encuentra la nota que es escripta en el registro que acuerda con la carta, que debe seer creido el escribano et non los testigos, et debe valer la carta.

Una vez tenga delante los libros de registro, será el propio alcalde el encargado de buscar y comprobar la existencia de las notas correspondientes al contrato de

33. Los protocolos notariales conservados entre los fondos del Archivo Histórico Provincial de Toledo comienzan en el año 1503 según su cuadro de clasificación, por lo que no podemos obtener datos sobre estos dos escribanos públicos del número por esta vía. <http://ccta.jccm.es/public_dglab/archivosHist/img/fondos_toledo.pdf>Consultado el 17-10-2015.

34. Editado por Morollón Hernández, Pilar: «Las ordenanzas municipales antiguas de 1400 de la ciudad de Toledo», Espacio, tiempo y forma. Serie III. Historia Medieval, 18 (2005), p. 389. No obstante, esta autora nos advierte que estas ordenanzas municipales de Toledo perderán su vigencia tras disponer Juan II en 1422 que Toledo se rigiera por las ordenanzas y privilegios de Sevilla, Morollón Hernández, Pilar, ibídem, p. 270.

35. Ostos SALCEDo, Pilar hace un somero repaso a los registros notariales castellanos que han sido publicados en el estudio introductorio que realiza en Registros notariales de Sevilla (1441-1442), Sevilla: Junta de Andalucía. Consejería de Cultura, 2010, pp. 17-18. 
censo, las cuales se transcribirán íntegramente a continuación. Haciéndolo de esta manera:

* Este día Luys Díaz de Toledo, secretario del rey, nuestro sennor, tomó la posesión de unas casas que son aquí en Toledo, a la collaçión de Santo Thomé, que ha por linderos casas de los herederos de maestre Manuel, físico, e casas de las espaldas destas dichas casas de Álvaro de Acre e de Diego de Acre. Las quales tenían dél a çenso infitheosy Lope Garçía de Acre e Teresa Garçía, su muger, de Catalina de Ferrera, fija de Diego Garçía de Ferrera; a la qual subçedió el dicho Luys Díaz; e después las tenía commo su heredero Ferránd Garçía de Acre, su fijo, por çierto preçio e con çiertas condiçiones segúnd que estava por contrabto público. E por quanto las dichas casas cayeron en comiso por non aver pagado el dicho çenso e tributo, tomó la dicha posesión dellas en haz e en paz de María Núnez, muger de Ferránd Garçía de Acre, e echola fuera e pidiolo por testimonio. Testigos: Juan Rodríguez de Sevilla, trapero, e Gonçalo Garçía de Monçón, escrivano de cámara, e Juan de Çespedes, escuderos de Luys Díaz.

* Este día, el dicho Luys Díaz las dio a çenso a María Núnez, muger del dicho Ferránd Garçía, por sý e commo madre e tutriz de Iohan e de Álvaro e Françisco e Teresa e Mayor e Beatriz, sus fijos e fijos del dicho Ferránd Garçía, por presçio cada anno de sieteçientos maravedís pagados por terçios. Su comienço del apoderamiento oy e su comienço de la primera paga el día de Nabidad del anno de çinquaenta e çinco, contando los annos venideros desde Santa María de Agosto deste anno, e con las condiçiones de los legos. Testigos: los dichos.

Podemos comprobar cómo uno de los asientos está dedicado al comiso de las casas debido al impago del canon anual del censo, señalando quién era la persona que disfrutaba de la casa y la razón por la que caía en la dicha pena de comiso. En cambio, el otro asiento trata de la constitución del censo enfitéutico, en la que se transfiere el dominio útil de las casas, a condición del pago de un canon anual. La extensión del asiento se desarrolla de forma breve: se indica que Luis Díaz de Toledo da a censo las casas a María Núñez y a sus hijos, estableciendo el precio y los plazos en que se debía de satisfacer. Únicamente se recoge en ella la referencia a una cláusula que se debía incluir en el instrumento público, aunque sin llegar a extenderla, anunciándola simplemente $e$ con las condiçiones de los legos; de esa manera el propietario evita que se pueda alegar cualquier tipo de inmunidad por parte de unos supuestos nuevos censualistas para no cumplir con el censo establecido. A pesar de ser esta la única condición expresa en la minuta, en la escritura pública sí aparecen otros tipos de cláusulas habituales en los censos enfitéuticos, puesto que el alcalde manda que se saquen de las notas contenidas en el libro de protocolos dos contratos de censo en la forma acostunbrada. La antigua poseedora y la destinataria del nuevo censo es la misma persona, por lo que nos preguntamos si se aprovecharía la ocasión para actualizar el precio a pagar. Lo que no se 
explícita en el registro es que las estipulaciones anteriores siguen vigentes en el actual contrato ${ }^{36}$. En el momento en que se eleven a escritura pública estas dos minutas se fusionarán en un único documento, utilizándose la primera de las notas como una exposición de motivos.

Asimismo, para determinar su autenticidad nuestro alcalde se basará en el testimonio de dos personas que conocían a Alfonso González de Segovia, y también su escritura, siendo uno de estos testigos escribano público y, por lo tanto, entendido en el arte de escribir, llegando a realizarse un peritaje caligráfico ${ }^{37}$. Se enfrentarán ante el siguiente cuestionario:

\begin{abstract}
E luego el dicho allcalde les preguntó sy conosçieron a Alfonso Gonçález de Segovia, escrivano público que fue en Toledo, defunto, que Dios perdone; e sy saben que antes e al tienpo que fallesçió fuese e era escrivano público desta dicha çibdad e por tal fuese avido e tenido e usava del dicho ofiçio; e sy saben que a sus escripturas e contrabtos era dada fe en juyzio e fuera dél; e otrosý sy saben o creen que un libro e protocolo que allí les fue mostrado sy avía seydo del dicho Alfonso Gonçález de Segovia, escrivano, e acostunbrava en él asentar e escrevir los contrabtos e otras escripturas que antél pasavan; e sy saben o creen que las minutas en el dicho registro asentadas, que suso van encorporadas, sy eran de letra del dicho Alfonso Gonçález de Segovia o parte dellas; o qué es lo que saben deste fecho.
\end{abstract}

Como resultado de él, confirmarán que se trata del libro registro de Alfonso González de Segovia. Pero las notas del registro que se correspondían al censo no estaban escritas por el notario titular difunto ${ }^{38}$; sin embargo los interpelados ratifican que una minuta anterior y otra posterior sí eran de su puño y letra, al igual que las anotaciones marginales que acompañan a cada uno de esos asientos, estando todas ellas en la misma hoja del registro. De todas formas, no se llega a identificar al autor material de las minutas del censo.

Es curioso cómo no se acude a los testigos que aparecen en la nota para corroborar que efectivamente el negocio había pasado ante el notario público fallecido,

36. Ostos Salcedo, Pilar: «Estudio», en Registros notariales de Sevilla (1441-1442), Sevilla: Junta de Andalucía. Consejería de Cultura, 2010, p. 49.

37. A estos peritos se recurre en la Partida 3.18.118, que trata cómo debe actuar el juez para determinar si una escritura pública ha sido falsificada, en caso de haber muerto o no encontrarse al escribano público que la ha autorizado y ante la duda sobre la autenticidad de la autoría se procede de la siguiente manera: et si por aventura el escribano non fuere vivo ó fuese en otra tierra tan lueñe que non podiesen haber para facerle esta pregunta, entonce debe el judgador tomar amas las cartas, et haber homes sabidores et entendudos consigo que sepan bien conoscer et entender las formas, et las feguras de las letras et los variamientos dellas, et débeles facer jurar que esto caten et escodriñen bien et lealmente, et que non dexen de decir verdat de lo que entendieren por ruego, nin por miedo, nin por amor, nin por desamor nin por otra razon ninguna. En la Partida 3.18.111 entre las razones por las que se podía desechar un documento autorizado por notario público se encuentra el que la escritura sea diferente a otras de ese mismo escribano, si éste afirma que es suya se necesita que homos bonos et conoscedores de letra que juren primero que digan verdad, et dixieren que aquella desemajanza es por razón de la tinta, ó del pergamino ó del tiempo en que fue fecha, mas que la materia de la letra una es asi como adelante mostramos. Es decir, en la legislación alfonsina se contempla el recurrir a «expertos» que determinen la autenticidad o no de escrituras públicas.

38. A excepción del comienzo de una de ellas, que es iniciada por el propio notario, pero la finaliza otra persona. 
puesto que ha transcurrido poco tiempo como para que hubieran fallecido to$\operatorname{dos}^{39}$. Por contra, hemos visto cómo se reclama la presencia de dos personas que sí habían conocido al difunto notario en vida para reconocer si realmente era su letra la que aparece en las notas del dicho negocio.

Las minutas del registro, ya hemos dicho, son transcritas en su integridad dentro del documento estudiado y nos muestran cómo en este caso, en particular, se limitan a recoger los datos esenciales del negocio. El examen del libro registro y de las notas llevado a cabo por el alcalde y las personas interrogadas nos permite obtener las siguientes conclusiones:

* Se tratan de notas breves redactadas de forma objetiva ${ }^{40}$.

* Cada asiento no estaría fechado individualmente ${ }^{41}$.

* Sí contarían con una pequeña anotación marginal, que consideramos posterior al registro de la nota puesto que se hace referencia al oficio de relator, el cual no heredaría de su padre hasta su fallecimiento, que se situaría en el año I457. Es decir, esas anotaciones se refieren al oficio o cargo del interviniente principal, que de esta manera queda identificado. Además del oficio, en el último de los asientos recogidos se añade una anotación calificativa de la clase del negocio jurídico que trata: çenso. La función de estas anotaciones no sería otra más que la de facilitar la búsqueda en el libro registro ${ }^{42}$. Evidentemente, al no haberse expedido ni entregado la escritura definitiva a las partes, tampoco encontraremos ninguna anotación del notario al respecto: estaríamos hablando de fecha, sacada o alguna expresión similar.

* No parece que hubiera intervención personal gráfica de los testigos en las notas, limitándose únicamente a reseñar sus nombres. Se trata, por otro lado, del único elemento de validación con la que contarían las minutas. En este caso son tres hombres, uno de ellos identificado como escribano de cámara, y todos ellos escuderos de Luis Díaz de Toledo. Sin embargo, no se hace referencia a su vecindad.

* Tampoco se hallaría ningún tipo de rúbrica autógrafa para cada uno de los asientos, así que suponemos que las notas registradas contenidas en el libro estarían validadas mediante la diligencia de apertura y cierre del libro registro ${ }^{43}$.

39. Partida 3.18.55

40. BONO HUERTA, José: Los archivos notariales, p. 21.

41. Para Bono Huerta, la práctica habitual es que existan unos epígrafes cronológicos, siendo las notas escritas a continuación de esa fecha; pero también cabe la posibilidad que algunas de las notas estuvieran fechadas y las siguientes hagan una remisión a esa datación. BONO HUERTA, José: Breve introducción a la Diplomática notarial española. Parte primera, Sevilla: Junta de Andalucía. Consejería de Cultura y Medio Ambiente, 1990, p. 35.

42. Obra Sierra, Juan María de la: «Los registros notariales castellanos», en Elena Cantarell Barella y Mireia COMAS VIA (coords.): La escritura de la memoria: Los registros, VIII Jornadas de la Sociedad Española de Ciencias y Técnicas Historiográficas, Barcelona: Promociones y Publicaciones Universitarias, 2011, p. 92.

43. Pilar Ostos SalCedo estudia los elementos de validación de los protocolos notariales anteriores a la Pragmática 
* No todos los asientos del registro los realizaría el propio notario titular, interviniendo varias manos, tal como demuestran las escrituras diferenciadas que se hallan en el registro. Indicándonos que aparte del fedatario, trabajaban con él en la notaría alguna persona más, lo que denota a su vez división del trabajo dentro de ella.

Según Bono Huerta, las notas comienzan a ser firmadas por los testigos a finales del siglo xv, y en ocasiones por el otorgante principal, pero no por los escribanos ${ }^{44}$. En nuestro caso, aparentemente nadie suscribe estas notas. Será a partir de la Pragmática de Alcalá de Henares de 1503, momento en que la nota se convierte en escritura matriz, cuando cada una de ellas será suscrita por los otorgantes, testigos y notario, aunque éste no hará su signo notarial ${ }^{45}$.

Aunque las notas estudiadas son del tipo breve, debemos tener en cuenta que en un libro registro es normal que convivieran con otros tipos de minutas (literales, extensas y enunciativas ${ }^{46}$, con lo que su redacción también podría ser objetiva o subjetiva, dependiendo de la situación. Con todo, la forma de proceder del notario a la hora de registrar la carta de censo difiere a lo ordenado cincuenta años atrás en las Ordenanzas municipales de Toledo, puesto que se habla de hacerlo de forma extensa ${ }^{47}$. En este capítulo dedicado a los registros notariales, fechado en I4OI, sin embargo no se explica cuál sería el modo de actuar con los registros cuando un escribano público falleciere o dejará el oficio por alguna otra causa.

La estructura diplomática de los asientos que aparecen en nuestra carta es la siguiente:

* Referencia cronológica, aunque más bien es una remisión.

* Identificación del otorgante.

* Detalles del asunto. En la primera de las minutas se incluye una exposición de motivos de por qué se llega a la pena de comiso de las casas.

* No se insertan cláusulas, salvo en el asiento dedicado al censo donde encontraremos la mención a una cláusula específica: condición de legos.

* Se cierran con la reseña de testigos, sin aparecer ninguna suscripción.

Con toda la información recopilada, el alcalde manda a Alfonso González de Valladolid, como notario que sustituye al titular difunto y que custodia sus libros de registro, que expida dos cartas de censo, una para cada parte, con todos los

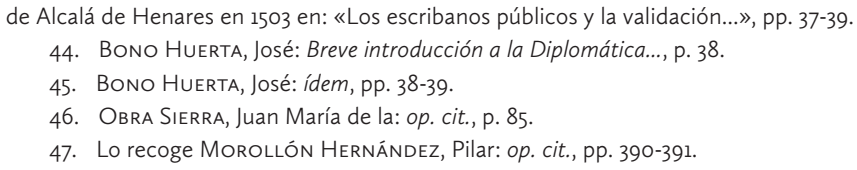


elementos requeridos por un instrumento público. Es decir, sendos documentos se redactarán bajo la iussio judicial del alcalde:

dixo que fallava e falló que devía mandar e mandó a mí, el dicho Alfonso Gonçaléz de Valladolid, escrivano, que por las minutas del dicho libro e protocolo del dicho Alfonso Gonçález de Segovia, escrivano, suso contenidas, sacase dos contrabtos de çenso en la forma acostunbrada e los signase con mi signo e los diese el uno dellos al dicho Juan Ximénez, en el dicho nonbre, e el otro contrabto a la dicha María Núnez, por sý e en nonbre de los dichos sus menores, con las solepnidades e çircunstançias que a él se requieren, non mudando sustançia alguna de derecho.

Ambas cartas son firmadas por el propio alcalde y signadas por el escribano público, de manera que así adquiriesen todo su valor jurídico commo sy el dicho Alfonso Gonçález de Segovia, escrivano, ante quien pasaron, los diera signados con su signo o commo mejor pueden e deven valer de derecho. De todas maneras, la licencia dada para expedir la escritura pública está limitada a esta carta de constitución de censo, puesto que en este documento no se menciona que el notario sucesor haya recibido una autorización general para todas aquellas notas que no se han formalizado por el fedatario difunto en un instrumento público ${ }^{48}$.

Es el momento en que se sacarán a partir de las notas del registro las escrituras públicas, explicitando que lo hace según la forma acostumbrada. El documento será extendido desde las notas, lo que supone un problema pues al estar extractadas la escritura no será desarrollada tal como la haría el notario que las formalizó, sino que el nuevo oficial desarrollará el instrumento público siguiendo su propio estilo. Para evitar estas dificultades aparejadas a las notas resumidas, se comenzará a exigir la redacción in extenso en los registros notariales ${ }^{49}$. Tal y como Alfonso XI ordenará en las Cortes de Valladolid celebradas en $1322^{50}$.

Gracias a todo este proceso observamos cómo la nota contará con pleno valor jurídico, porque a ella se recurre, como hemos mostrado, para confeccionar el documento definitivo y completo ${ }^{51}$, al que se le agregan todos los elementos formales y solemnidades requeridos por la legislación, aunque la suscripción del notario que toma la nota es sustituida por la del que confecciona el instrumento público, que lo firma y signa, añadiéndose además la firma de la autoridad judicial (el alcalde). Dada la importancia de la nota no es extraño que en la legislación alfonsina se incida tanto en la obligación del notario para conservar los libros de registros ${ }^{52}$.

\footnotetext{
48. BONO HUERTA, José: «Modos textuales de transmisión...», pp. 97-98.

49. BONO HUERTA, José: Breve introducción a la Diplomática..., p. 40.

50. Lo menciona MARChANT Rivera, Alicia: «La expedición del documento notarial castellano en el tránsito a la modernidad: de la nota registral a la matriz del protocolo notarial», [en línea] III Seminario de Diplomática. Paseo documental por el ayer madrileño. Universidad Complutense de Madrid. Facultad de Geografía e Historia. 16, 17 y 19 de octubre de 2015 , p. 8.

51. Obra Sierra, Juan María de la: op. cit., p. 80.

52. Aunque en Fuero Real 1.8.2 se habla de conservar las propias notas, tanto en Espéculo 4.12 .8 como en Partida 3.19.9 se refieren ya al libro registro de las notas, con la pretensión de recurrir a ellos en caso de perderse o existir alguna duda sobre la escritura original para reexpedir un nuevo documento o comprobar la fidelidad de los datos recogidos.
} 


\section{LA CARTA DE CONSTITUCIÓN DE CENSO ENFITÉUTICO}

La separación entre las dos partes del documento (petición y mandamiento para extender la escritura pública y la propia carta de constitución de censo) se hará gráficamente con una línea horizontal, que ocupa el ancho que queda sin escriturar del último renglón del primer apartado, y con un ligero espacio en blanco entre líneas con la finalidad que sea visible dónde acaba una y dónde empieza la otra.

Pero antes de pasar a analizar la carta de censo, apuntaremos que en la Partida 3.I8.69 se indica cómo debían realizarse, pero éste no sería el modelo para los censos enfitéuticos. Por su parte, en la Partida 5.8.28 se expresa que estos negocios son lo más parecido a los logueros, es decir, alquileres. No obstante, en el formulario de la Partida 3.I8 tampoco hay ningún ejemplo específico para el tipo documental que estamos tratando.

La carta de censo enfitéutico objeto de nuestro estudio se desarrolla de forma similar a otras escrituras de la misma tipología documental ${ }^{53}$. Tiene una redacción subjetiva, que, como ya hemos dicho anteriormente, contrasta con la manera de redactar las minutas, pues lo eran de forma objetiva. Siendo su estructura diplomática como sigue:

Es comenzada con la notificación general, en la que se da el calificativo del tipo documental: Sepan quantos esta carta de çenso ynfitheosy vieren. Para a continuación presentar al otorgante principal, tratándose del censualista, Luis Díaz de Toledo, dueño de las casas que serán objeto de censo. De él tan sólo nos darán el oficio que estaba ejerciendo en esos momentos: secretario del rey.

Mientras, la identificación de la persona que recibe a censo las casas la encontraremos subsumida dentro de la disposición. Es aquí donde se nos muestran los datos del negocio y su desarrollo. La fórmula de acceso al dispositivo es la clásica otorgo e conozco por esta carta, dándose y apoderándose a censo enfitéutico, teniendo éste además un carácter perpetuo (para agora e para sienpre jamás) a María Núñez, viuda de Fernán García de Acre, que actuará también en nombre de sus hijos. Siendo el objeto del censo las casas que tiene el censualista en la collación de la iglesia de Santo Tomé. De esas casas se dará su ubicación y los lindes para su correcta identificación. Dentro de exposición de motivos hallaremos la fórmula de procedencia y propiedad de los bienes, en la que se explica cómo Luis Díaz de Toledo sucederá a una tal Catalina de Ferrera en el dominio directo de las casas: Las quales dichas casas tenía el dicho Ferránd Garçía de Acre, vuestro marido, a çenso de Catalina de Ferrera, a la qual yo subçedí, e las el dicho Ferránd Garçía ovo por

53. Por poner un ejemplo mencionaremos el estudiado por González de LA PeÑA, María del Val: «Estudio diplomático de los censos de la iglesia mayor y colegial de San Justo y Pastor de Alcalá de Henares», en Actas del III Encuentro de Historiadores del Valle del Henares, Guadalajara: Institución Marqués de Santillana. Institución de Estudios Complutenses (CSIC). Centro de Estudios Seguntinos y Ayuntamiento de Guadalajara, 1992. pp. 175-188. 
subçesión e herençia de su padre e madre. Asimismo nos muestra el motivo para que se produjera con anterioridad el comiso de estos bienes: por non aver pagado el çenso e tributo que las dichas casas e el dicho Ferránd Garçía era obligado las yo tomé por yncomiso e me apoderé dellas e de la tenençia e posesión dellas, es decir, el impago del censo por parte del dicho Fernán García. Se correspondería el contenido con la primera de las minutas, pero no así en su redacción, puesto que el escribano público que extenderá la carta no la copiará literalmente del registro, sino que hará su propia interpretación, dándole otra redacción, incluso obviando algunos datos. El marido difunto de María Núñez, habría heredado esas edificaciones de sus padres, Lope García de Acre y Teresa García, siendo ellos mismos censualistas de Catalina de Ferrera. Pues bien, en la carta de censo se obvian los nombres de los padres del difunto poseedor del dominio útil de estas propiedades ya dichas.

Tenemos que decir que Fernán Díaz de Toledo, el padre del censualista, era judeoconverso ${ }^{54}$. Quizás por ello, las mencionadas casas se encuentran situadas en la collación de Santo Tomé que, aunque habitada por cristianos, estaría integrada en la judería de Toledo ${ }^{55}$. Por contra, no hemos encontrado referencias a Catalina de Ferrera en la documentación consultada, por lo que desconocemos la vinculación existente con Luis Díaz de Toledo para que los inmuebles que son objeto del censo pasaran a su poder.

Antes de encontramos la fórmula de pertenencia y accesorios, tendremos una reiteración del verbo dispositivo. Con esta fórmula de pertenencia se expresa que el censo afectaría a la totalidad del bien:

E dovos e apodérovos las dichas casas suso deslindadas, con todas sus entradas e salidas e con todas sus pertenençias, quantas han e aver deven e les pertenesçen e pertenesçer deven en qualquier manera e por qualquier razón.

Seguida por el período señalado en la que entraría la censataria y sus hijos a disfrutar del dominio útil, así como su vigencia, que, como ya hemos dicho, se trataría a perpetuidad: para que desde oy día de la fecha e otorgamiento desta carta para sienpre jamás las dichas casas sean vuestras.

Encontraremos también la fórmula que expresa la trasmisión del dominio a la censataria, acompañada de la entrega de la posesión para que el comprador pueda tomarla sin que se haga necesaria la presencia del censualista o de la autoridad judicial ${ }^{5}$ :

54. Sanz Fuentes, María Josefa: «El testamento de Fernán Díaz de Toledo...», p. 384

55. Porres Martín-Cleto, Julio: «Algunas precisiones sobre las juderías toledanas», Anales toledanos, 16 (1983), p. 38 .

56. Ostos Salcedo, Pilar: Notariado, documentos notariales y Pedro González de Hoces, veinticuatro de Córdoba Sevilla: Universidad de Sevilla. Secretariado de Publicaciones, 2005, p. 146. 
para que podades fazer e fagades dellas e en ellas e con ellas todo lo que vos e ellos quisierdes e por bien tovierdes commo de cosa vuestra misma propia para dar e vender e trocar e canbiar e enpennar e enajenar.

Sin embargo, a continuación pronuncia una condición, que no es otra que el pago de un censo anual en los plazos señalados:

\begin{abstract}
a tal pleito e con tan condiçión: que vos e los dichos vuestros fijos e vuestros herederos para agora e para sienpre jamás, e otra qualquier persona o personas que las dichas casas tovier e oviere en qualquier manera, dedes e paguedes e den e paguen de çenso e tributo en cada un anno para sienpre jamás seteçientos maravedís.
\end{abstract}

La cuantía del censo es de 700 maravedís anuales, dividiéndose entre tres pagas, estableciéndose además las fechas en que debían de hacerse. Los momentos del pago señalados son las siguientes festividades cristianas: Santa María de Agosto (Asunción de la Virgen - I5 de agosto), Pascua de Navidad (25 de diciembre) y Pascua Mayor (domingo de Resurrección, fecha móvil en el calendario litúrgico que podía caer entre el 22 de marzo y 25 de abril), que también debían realizarse a perpetuidad.

En el contrato se establece una serie de condiciones para la censataria. La primera que nos encontramos la acabamos de ver: el pago de la cuantía establecida en los plazos señalados: E asý desde en adelante en cada un anno a otros tales plazos para sienpre jamás.

A la hora de disponer la transmisión del dominio útil, se permitía toda una serie de acciones sobre la propiedad (dar e vender e trocar e canbiar e enpennar e enajenar). No obstante, tras establecer el importe del censo y los términos de su satisfacción, se expresa la prohibición de vender o enajenar las casas a instituciones o personas de determinada condición social:

\footnotetext{
que non podades dar nin vender nin enajenar las dichas casas, vos nin los dichos vuestros fijos nin otra qualquier persona o personas que las tovieren e ovieren, a cavallero nin a escudero nin a duenna nin a donzella nin a ospital nin a cofadría nin a cruzada nin a monasterio nin a omne nin muger fijosdalgo nin de orden nin de religión nin a judío nin a moro nin a otra alguna nin algunas personas de las que los derechos defienden, a omnes o a muger llanos, abonados e contiosos, e tales que den e paguen los dichos seteçientos maravedís del dicho çenso e tributo en cada un anno para sienpre jamás.
}

Esta locución vendría dada por la diversidad de jurisdicciones y fueros procesales existentes en la época medieval, de manera que cabría la posibilidad de escapar de la justicia real alegando algún tipo de inmunidad. Con esta condición se busca que ante un hipotético nuevo censatario no pudiese alegar su jurisdicción para ampararse bajo ella como modo de evitar demandas ante un posible incumplimiento del contrato. Amén de esto, a su vez se pretende que la persona 
que se hace con el dominio útil pueda hacer frente al pago del censo ${ }^{57}$. Esta es la condición de legos a la que se hace referencia en la minuta que aparece en el libro registro del notario difunto.

En otro lugar hemos dicho que el título 8 de la Partida 5 está dedicado a los logueros et de los arrendamientos. Es al final del mismo donde encontraremos las dos únicas leyes que afectan a los censos enfitéuticos, y de las que hallaremos referencias en nuestra carta.

Siguiendo con el hilo anterior, para poder llevar a cabo la venta ${ }^{58}$ se tiene que comunicar al dueño del dominio directo de la intención de vender el bien, de manera que pudiera ejercer el derecho de tanteo por si éste quisiera recuperar el dominio útil de las casas comprándoselas al mismo precio en que se vendieren ${ }^{59}$. En caso de no querer comprarle el bien, le dará su autorización para que lo pueda enajenar, llevándose, en este caso, la mitad del precio recibido ${ }^{60}$, lo cual se hace en reconocimiento del derecho de laudemio por ser el propietario del dominio directo de las casas ${ }^{6 \mathrm{r}}$ :

E que cada vez que fueren vendidas o traspasadas seades e sean obligados de me pagar a mí, o a los dichos mis herederos después de mí, la çinquantena parte del preçio porque asý fueren vendidas e traspasadas cada vez que fueren vendidas e traspasadas en [reco]nnosçimiento al utile directo e dominio que commo a sennor propretario de las dichas casas he e me pertenesçe.

En la Partida 5.8.28 se recoge la posibilidad que el censualista se viera eximido de pagar la renta por si alguna causa natural el bien se perdía. En esa misma ley se establece la pena de comiso si se están dos o tres años sin pagar la renta, lo cual dependerá de qué condición es el censatario: eclesiástico o lego. Como veremos a continuación, la exención de renta por pérdida natural del bien no se recoge en nuestro documento, pero sí la pena de comiso por impago, que se establece en caso de incumplimiento del pago del canon anual durante tres años seguidos. Sin embargo, se le da la opción al censualista entre tomar las casas o no, con lo que seguiría cobrando el censo establecido. Si se decantará por tomar las casas supondría la pérdida del dominio útil por parte del censatario, de este modo se le priva de la posesión del bien. Esa pena de comiso, hemos visto, se habría llegado a aplicar en una ocasión anterior, lo que supuso la necesidad de realizar un nuevo contrato de censo enfitéutico.

57. Con las locuciones lego, llano y abonado o lego, llano, liso y abonado «se explican las calidades que debe tener el fiador ó depositario, esto es, que no goce fuero eclesiástico, ni de nobleza, ni otro privilegio, y que tenga hacienda», Diccionario judicial, que contiene la explicación y significación de las voces que están más en uso en los tribunales de Justicia, Madrid: Imprenta de D. Miguel de Burgos, 1831, pp. 155-156.

58. Se regula en la Partida 5.8.29.

59. Sin embargo, en la escritura no se indica un plazo para este trámite.

60. Este es el máximo que podía percibir el dueño del dominio directo según la Partida 5.8.29.

61. El mismo porcentaje aparece en la mencionada ley de la Partida. 
E otrosý, que sy estovierdes vos, o los dichos vuestros herederos después de vos o otra qualquier persona o personas que las dichas casas tovieren e ovieren, tres annos continuos, uno en pos de otro, que non dierdes nin pagáredes nin dieren nin pagaren el dicho çenso e tributo commo dicho es, que por el mismo fecho las dichas casas, con lo que en ellas más ovierdes fecho, labrado e mejorado, ayan caýdo e cayan en la pena del comiso de averlas perdido e las perdades e pierdan; e por la dicha pena de yncomiso vos la puedan e /3v. puedan tomar por mi propia attoridad e suya syn mandado de allcalde nin de juez e syn fuero e syn pena alguna, e que en escogençia mía o de los dichos mis herederos sea de vos tomar las dichas casas por la dicha pena o de vos las dexar e cobrar de vos e de los dichos vuestros herederos el dicho çenso e tributo.

La pena de comiso, el derecho de tanteo y el laudemio son derechos que corresponden al dueño por el dominio directo y que se remontan a época de Justiniano (primer tercio del siglo vi), siendo característicos de este tipo de censos enfitéuticos ${ }^{62}$.

Por otro lado se fija la obligación de conservar y reparar las casas para mantener el valor del bien acensuado, de manera que el propietario del dominio directo no tuviera que invertir en su mantenimiento, quedando a cargo en exclusiva del censatario. Al mismo tiempo, se pretender evitar una pérdida del valor del bien por dejación de su cuidado, de esta forma el censualista no se vería perjudicado en caso de tener que recuperar el dominio útil de la propiedad ${ }^{63}$ :

\begin{abstract}
E dovos las dichas casas commo dicho es a çenso, enfiestas e adobadas e reparadas, e que vos, e los dichos vuestros herederos e subçesores después de vos o otra qualquier persona o personas que las tovieren e ovieren, seades e sean tenudos de las tener enfiestas, adobadas e reparadas para sienpre jamás.
\end{abstract}

Hasta ahora todas las cláusulas vistas son específicas de los censos. Seguidamente se encuentran una serie de cláusulas especiales que se dan en otros tipos documentales. Comenzando por la renuncia que hace el censualista a la excepción del engaño ${ }^{64}$, la cual se vería reforzada por la renuncia al ordenamiento de Alcalá de Henares ${ }^{65}$ :

E otorgo e oblígome de vos non quitar nin serán quitadas las dichas casas que vos asý do e apodero a çenso por más nin por menos nin por al tanto nin por la meytad más nin menos del justo e medio justo preçio nin por otra razón alguna en ninguna nin alguna manera, sobre lo qual renunçio la ley nueva real quel noble rey don Alfonso, que Dios perdone, fizo e ordenó en las Cortés de Alcalá de Henares que fabla en este caso.

62. Amparo Trujillo, María Amparo: «El documento de censo...», p. 320.

63. Moreno Trujillo, María Amparo: «Diplomática notarial en Granada en los inicios de la Modernidad (15051520)», en El notariado andaluz en el tránsito de la Edad Media a la Edad Moderna: I Jornadas sobre el notariado en Andalucía, Sevilla: Colegio Notarial de Sevilla, 1995, p. 118.

64. Fuero Real 3.10.5 y Partida 5.5.56.

65. Ordenamiento de Alcalá, título 17, ley única. 
De esta manera se evita una posible rescisión del contrato por no haber recibido el precio justo y, por otro lado, se asegura al censatario que el canon anual siempre será de 700 maravedís. Por contra, no se da la habitual donación de lo que falte para llegar al justiprecio, lo que se puede interpretar como que el censatario no cierra la puerta a futuras reclamaciones dado el caso.

También se recogen la obligación de saneamiento y evicción ${ }^{66}$, la obligación de salir en defensa en caso de juicio, siendo reforzadas por una obligación general de bienes:

E otrosý otorgo de aver por firme, estable e valedero para agora e para sienpre jamás este dicho apoderamiento de çenso que de las dichas casas vos fago e de non yr nin venir contra ello nin contra parte dello yo nin otri por mí en tienpo alguno nin por alguna manera, e de vos redar e defender e anparar e fazer sanas e de paz estas dichas casas que vos do e apodero a çenso de qualquier persona o personas que vos las demande, enbargue o contralle en qualquier manera e por qualquier razón, e tomar la boz del pleito que sobre la dicha razón vos fueren movidos e los seguir e proseguir e vos sacar a paz e a salvo en tal manera que vos e los dichos vuestros fyjos e herederos $t e<n>$ gades las dichas casas apoderadas a çenso e por el dicho çenso para agora e para sienpre jamás en paz e en salvo syn contrario nin enbargo alguno.

Todas ellas con miras a proteger la posesión del dominio útil de las casas ante cualquier eventual circunstancia que pusiera el peligro su disfrute. Es decir, garantizan la tenencia del bien ante posibles demandas. En el caso de que se produjera un pleito, el censatario se compromete a intervenir en favor del censualista y defenderlo hasta afirmarle en su posesión.

A partir de este momento comienza la participación documental de la censataria, quien, en su nombre y en la de sus hijos, muestra su conformidad con el contrato, aceptando el censo y las condiciones impuestas en esta carta, obligándose a respetarlo y al pago del canon anual de los 700 maravedís. En caso de incumplimiento, se impondría una pena pecuniaria que consistiría en pagar el doble de esa cantidad. Pero aunque se pagase la pena, no supondría que el contrato se habría de dar por roto, debiendo seguir satisfaciendo el censo anual. Todo lo dicho se verá afianzado por parte de la censataria al hacer una obligación general sobre su persona y bienes, presentes y futuros. Este tipo de obligaciones buscan cerciorar el cumplimiento del contrato por parte de la persona que la enuncia.

También se produce una actuación conjunta del censualista y la censataria para establecer su sumisión a la justicia para que se les exija el cumplimiento del contrato, determinándose que si alguna de las partes incumpliere con lo acordado debe indemnizar a la otra. El sometimiento a las justicias del rey, dándoles poder para obligar a llevar a efecto las estipulaciones contenidas en el documento, supone que ambas partes se verán forzadas a cumplir con el contrato por vía

66. Regulada en Fuero Real 3.10.7; Espéculo 4.12.35, 36 y 37; Partida 5.5.32, 33 y 35; y Partida 3.18.56. 
judicial. Ese acatamiento es acompañado por una cláusula ejecutiva, con la que ya no tendrían la posibilidad de presentar algún tipo de recurso contra la resolución de la justicia al darse como concluido el juicio.

Ambas partes igualmente renunciarán a una serie de leyes para evitar dilaciones en caso de pleito, expresándose de la siguiente manera:

E renunçiamos que non podamos aver nin demandarnos, nin alguno de nos nin otri por nos, plazo de terçer día nin ferias de pan nin de vino $\mathrm{cojer}^{67}$ nin traslado desta carta nin plazo de abogado ${ }^{68}$ nin de acuerdo nin otro plazo alguno de fuero nin de derecho.

No podía faltar tampoco la clásica renuncia general a las leyes que establezcan algún tipo de beneficio. Pero debido a la existencia de una ley que prohíbe renuncias generales de leyes, también se renunciará a ella ${ }^{69}$.

Por su parte, la censualista, al ser mujer, renunciará específicamente a las leyes que impiden que las mujeres se puedan presentar como fiadoras u obligar sus bienes a una deuda ajena ${ }^{70}$. Dejando, además, constancia de quedar enterada de las consecuencias de renunciar a esas leyes que la protegían. Con ella se pone punto y final al apartado de las cláusulas documentales:

E yo, la dicha María Núnez, renunçio la $>$ s< ley>es< del derecho que dizen que la muger non puede ser fiadora nin obligar sus bienes a debdo ajeno. Las quales dichas leyes me fueron fechas entender, que me non valan.

Como hemos visto, se trata de renuncias a derechos legales, en concreto a una serie de protecciones, tanto generales como específicas, que se encuentran en la legislación. Estas renuncias pretenden conseguir dar una mayor seguridad al respeto de lo acordado en el documento al evitar posibles impugnaciones posteriores o alegar su ineficacia legal ${ }^{71}$.

En la corroboración se deja constancia de la elaboración de originales múltiples, entregándose un instrumento a cada una de las partes, los cuales tendrían el mismo tenor documental e iguales elementos de validación, de manera que ambas cartas tuvieran la misma fuerza legal. Se indica que se otorgan delante del escribano público y de los testigos, pero sin hacer referencia que hubiera sigo

67. Espéculo 4.4.10; Partida 3.3.34, 36 y 37.

68. Ordenamiento de Alcalá, título 3, ley única. De los abogados: que plaço deve aver el que los pidiere.

69. Para ampliar detalles sobre esta renuncia nos remitimos a Pérez PREndes MuÑoz de ArRACo, José Manuel: «"General renunciación non vala": sobre doctrina y práctica en tiempo del "ius comune", Glossae: Revista de Historia del Derecho europeo, nº 5-6 (1993-1994), pp. 75-114.

70. En concreto la Partida 5.12.2. Mientras, en la Partida 5.12.3 se recoge los casos en que sí se podría presentar como fiadora. En el Fuero Real 3.18.5 se declaran como inválidas las fiadurías que establecen las mujeres sin consentimiento de sus maridos, por lo que en este caso no afectaría a nuestra protagonista por ser viuda.

71. BOnO Huerta, José: Breve introducción a la Diplomática..., p. 63. 
rogado el notario para que confeccionara el instrumento público y para que los testigos estuvieran presentes.

Se cierra el tenor documental con la data tópica y crónica ${ }^{72}$ y la nómina de testigos presentes, siendo su número tres, encontrándose entre ellos un escribano de cámara, y todos ellos escuderos del censatario. Es aquí donde se expresa que los testigos habían sido llamados y rogados para que hicieran acto de presencia al otorgamiento.

La suscripción y signo del notario ante el que fue otorgado este negocio, y que escritura en su libro de registro, es sustituida por la firma y rúbrica del alcalde Gonzalo de la Fuente y por la suscripción del notario que sustituye al primero en el oficio. La firma autógrafa del alcalde como autoridad judicial, muestra de su intervención en el documento, no excluye la aparición de la suscripción y signo notarial, con las cuales se perfecciona y finaliza el documento notarial.

En esa suscripción notarial explicará que saca, con autorización y licencia del alcalde, dos instrumentos públicos a partir de la minuta del registro notarial del escribano público fallecido, entregando una carta a cada una de los partes. La que ha sido objeto de estudio es la que habría recibido Juan Jiménez que, recordamos, actuaba en nombre del censatario Luis Díaz de Toledo. El último elemento que aparece en esta carta es el signo notarial y su firma y rúbrica.

\footnotetext{
Yo, Alfonso Gonçález de Valladolid, escrivano público de los del número de la muy noble çibdad de Toledo, fuy presente antel dicho allcalde a todo lo que dicho es. De liçençia e autoridad, de la qual que aquý firmó su nonbre, e de pedimiento del dicho Juan Ximénez, en el dicho nonbre, dos contratos de çenso por la minuta del libro e protocolo del dicho Alfonso Gonçález de Segovia, escrivano defunto, fielmente saqué para cada una de las dichas partes el suyo. De los quales, uno dellos es este para el dicho Juan Ximénez e va escrito en estas quatro fojas deste pergamino, escritas de amas partes, con esta en que va my signo, e en fin de cada plana va puesta una de las rúbricas de mi nonbre e salvadas las emiendas que ya. E por ende fiz aquý este mío sig (signo) no en testimonio de verdad.
}

Alfonso Gonçález (rúbrica).

En el cierre de la expedición de la escritura definitiva, el escribano público no señala los testigos presentes. Sí lo ha hecho anteriormente al finalizar la primera parte del documento, mostrando que lo habían sido del proceso de peritaje del libro de registro y del mandamiento del alcalde para que se sacasen los contratos de censo debidamente autorizados. Hay que indicar que este cierre tampoco coincide con el que aparece en la Partida $3 \cdot 18.55^{73}$, aunque sí se expresa la fidelidad de los contratos con la información hallada en el libro de registro.

72. Se corresponde a la fecha de la formalización del negocio que había recogido el notario en el libro registro.

73. Recordamos que en esta ley se regula cómo se actuaba a la hora de expedir un documento público tras la muerte del notario que lo había recogido en su libro registro. 


\section{BIBLIOGRAFÍA}

Bermejo Cabrero, José Luis: «Los primeros secretarios de los reyes», Anuario de Historia del Derecho Español, 49 (I979), nº 4, pp. I86-296.

BONO HUERTA, José: «Modos textuales de transmisión del documento notarial medieval», Estudis Històrics i Documents dels Arxius de Protocols, xIII (1995), pp. 75-I04.

—: «Conceptos fundamentales de la Diplomática notarial», Historia. Instituciones. Documentos, I9 (I992), pp. 73-88.

-: Breve introducción a la Diplomática notarial española. Parte primera, Sevilla: Junta de Andalucía. Consejería de Cultura y Medio Ambiente, I990.

-: Los archivos notariales, Sevilla: Junta de Andalucía. Dirección General del Libro, Bibliotecas y Archivos, I985.

-: Historia del Derecho notarial español, I.2, Madrid: Junta de Decanos de los Colegios Notariales de España, I982.

CAÑAS GÁlvez, Francisco de Paula: Burocracia y cancillería en la corte de Juan II de Castilla (I406-I454). Estudio institucional y prosopográfico, Salamanca: Ediciones Universidad de Salamanca, 2012.

DíAz DE Toledo, Fernán: Notas del relator, [en línea] Sevilla: I50o.

$<$ http://bdh-rd.bne.es/viewer.vm?id=00ooI77078\&page $=$ I $>$ [consultado 30 de diciembre 20I5]

Diccionario judicial, que contiene la explicación y significación de las voces que están más en uso en los tribunales de Justicia, Madrid: Imprenta de D. Miguel de Burgos, I83I.

Dios, Salustiano de: El Consejo Real de Castilla (1385-I522), Madrid: Centro de Estudios Constitucionales, I982.

GonZález de la Peña, María del Val: «Estudio diplomático de los censos de la iglesia mayor y colegial de San Justo y Pastor de Alcalá de Henares», en Actas del III Encuentro de Historiadores del Valle del Henares, Guadalajara: Institución Marqués de Santillana. Institución de Estudios Complutenses (CSIC). Centro de Estudios Seguntinos y Ayuntamiento de Guadalajara, I992. pp. I75-188.

López Villalba, José Miguel: «Ordenanzas señoriales y vida cotidiana en el comienzo de la Edad Moderna segoviana», Studia Historica. Historia Medieval, 32 (20I4), pp. 239-270.

MARCHANT Rivera, Alicia: «La expedición del documento notarial castellano en el tránsito a la modernidad: de la nota registral a la matriz del protocolo notarial», [en línea] III Seminario de Diplomática. Paseo documental por el ayer madrileño. Universidad Complutense de Madrid. Facultad de Geografía e Historia. I6, I7 y I9 de octubre de 2015.

<http://dspace.uma.es/xmlui/bitstream/handle/10630/10612/La\%2oexpedici\%C3\%B3n\%2odel\%20 documento\%2onotarial\%2ocastellano\%2oen\%2oel\%20tr\%C3\%AInsito\%20a\%2ola\%2oModernidad.De\%2ola\%2onota\%2oregistral\%20a\%2ola\%2omatriz\%2odel\%2oprotocolo\%20 notarial.pdf? sequence $=I>$ [consultado 24 diciembre 20I5]

Martínez Díez, Gonzalo: «El Fuero Real y el Fuero de Soria», Anuario de Historia del Derecho Español, 39 (I969), pp. 545-562.

Moreno TrujlLlo, María Amparo: «Diplomática notarial en Granada en los inicios de la Modernidad (1505-I520)», en El notariado andaluz en el tránsito de la Edad Media a la 
Edad Moderna: I Jornadas sobre el notariado en Andalucía, Sevilla: Colegio Notarial de Sevilla, I995, pp. 75-I26.

-: «El documento de censo en la Castilla del siglo xvi», Revista de Derecho Notarial, CXLV-CXLVI (julio-diciembre, I989), pp. 313-37I.

Morollón Hernández, Pilar: «Las ordenanzas municipales antiguas de I40o de la ciudad de Toledo», Espacio, tiempo y forma. Serie 1II. Historia Medieval, I8 (2005), pp. 265-440.

Obra Sierra, Juan María de la: «Los registros notariales castellanos», en Elena CANTARELl BARElla y Mireia CoMAS VIA (coords.): La escritura de la memoria: Los registros, VIII Jornadas de la Sociedad Española de Ciencias y Técnicas Historiográficas, Barcelona: Promociones y Publicaciones Universitarias, 20II, pp. 73-IIO.

Opúsculos legales del rey don Alfonso el Sabio: publicados y cotejados con varios códices antiguos por la Real Academia de la Historia. Tomo i: El Espéculo o Espejo de todos los derechos. Madrid: Imprenta Real, I836.

Opúsculos legales del rey don Alfonso el Sabio: publicados y cotejados con varios códices antiguos por la Real Academia de la Historia. Tomo II: El Fuero Real, las leyes de los adelantados mayores, las nuevas y el ordenamiento de las tafurerías, y por apéndice las leyes del estilo. Madrid: Imprenta Real, I836.

Ostos Salcedo, Pilar: «Estudio», en Registros notariales de Sevilla (I44I-I442), Sevilla: Junta de Andalucía. Consejería de Cultura, 20ıо, pp. II-I7.

-: «Los escribanos públicos y la validación documental», en La validación de los documentos: pasado, presente y futuro: octavas jornadas archivísticas, Huelva: Diputación Provincial de Huelva, 2007, pp. 27-42.

-: Notariado, documentos notariales y Pedro González de Hoces, veinticuatro de Córdoba, Sevilla: Universidad de Sevilla. Secretariado de Publicaciones, 2005.

-: «Una renovación documental sevillana (s. XIv)», Historia. Instituciones. Documentos, I9 (I992), pp. 307-3I6.

Pérez Prendes MuÑoz de ArRaco, José Manuel: «"General renunciación non vala”: sobre doctrina y práctica en tiempo del "ius comune", Glossae: Revista de Historia del Derecho europeo, $\mathrm{n}^{\circ}$ 5-6 (I993-I994), pp. 75-II4.

Porres Martín-Cleto, Julio: «Algunas precisiones sobre las juderías toledanas», Anales toledanos, I6 (I983), p. 37-57.

Registros notariales de Sevilla (I44I-I442), Sevilla: Junta de Andalucía. Consejería de Cultura, 2010.

SÁNCHEZ, Galo: Fueros castellanos de Soria y Alcalá de Henares, Madrid, I9I9.

SAnz Fuentes, María Josefa: «El testamento de Fernán Díaz de Toledo, el relator (I455)», Historia. Instituciones. Documentos, 4I (2014), pp. 38I-406.

-: «La escritura gótica documental en la Corona de Castilla», en María Josefa SANZ FuEnTES y Miguel CALleja PUERTA (coords.): Las escrituras góticas desde I250 hasta la imprenta. $\checkmark$ Jornadas de la Sociedad Española de Ciencias y Técnicas Historiográficas, Oviedo: Universidad de Oviedo, 2010, pp. I07-I26.

Las Siete Partidas del rey don Alfonso el Sabio: cotejadas con varios códices antiguos por la Real Academia de la Historia. Madrid: Imprenta Real, 1807. 3 vol. 
Calidad de Revistas

científicas Españolas

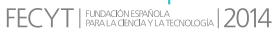

SERIE III HISTORIA MEDIEVAL

REVISTA DE LA FACULTAD DE GEOGRAFİA E HISTORIA
AÑO 2016

ISSN: 0214-9745

E-ISSN 2340-1362

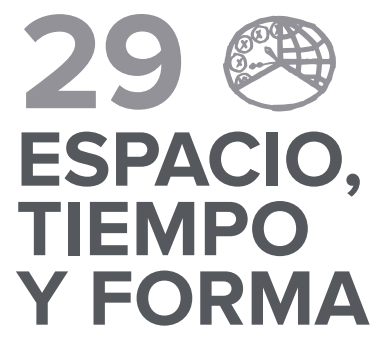

\section{Artículos}

17 Leticia Agúndez San Miguel

El tumbo de San Pedro de Montes como instrumento de recreación de la memoria instituciona

\section{Roberto Antuña Castro}

La copia de escrituras públicas a la muerte del notario titular

75 Carlos de Ayala Martínez

Alfonso VIII, Cruzada y Cristiandad

\section{Carlos Barquero Goñ I}

La renta señorial de la Orden de San Juan en Castilla durante los siglos XII y XIII

\section{MARgARITA CABRERA SÁNCHEZ}

Cristianos nuevos y cargos concejiles. Jurados conversos en Córdoba a fines del Medievo

183 Francisco de Paula Cañas Gálvez

La correspondencia de Leonor de Alburquerque con su hijo Alfonso $V$ de Aragón: acción política y confidencia familiar del partido aragonés en la corte de Castilla (1417-1419)

\subsection{Octavio Colombo} del siglo XV

os dueños del dinero. Prestamistas abulenses a mediados

\section{Alfonso Domínguez de LA CONCHA \\ Apropiaciones de comunales en la Puebla de Guadalupe} (Cáceres) durante la Baja Edad Media

\section{Antonio Vicente Frey SÁnChez}

Sobre la articulación administrativa de la cuenca del río Segura entre los siglos VII y VIII: algunos recientes elementos para identificar una frontera «blanda»

\section{David Gallego VALLE}

La fortificación medieval en el Campo de Montiel (ss. VIII-XVI). Análisis de su secuencia histórica y constructiva

\section{MAURICIO HERRERO JIMÉNEZ}

El cuidado del alma y otros cuidados en las cartas de aniversario del cabildo de los clérigos de Cuéllar en el siglo XIV
4.01 JaIME DE HOZ OnRUBIA

Antroponimia y reconstrucción histórica: consideraciones sobre la identificación personal en el paso de la Edad Media a la Moderna en la Corona de Castilla

\section{Carmen López Martínez \\ Sancho IV de Castilla y la imposición del diezmo mudéjar} en Murcia

\subsection{PABlo Martín Prieto} el valor de los preámbulos

Idea e imagen del rey en la diplomática medieval hispana:

\section{Luis Martínez García}

Los campesinos al servicio del señor, según los fueros locales burgaleses de los siglos XI-XIII

54.3 Juan José Morales Gómez

Las minas de alumbre del bajo jiloca (Zaragoza) y su explotación a fines de la Edad Media

571 DAVID D. NAVARRO

Precisiones literarias sobre el antijudaísmo de Gonzalo de Berceo en el Milagro de Teófilo (XXIV)

593 JaIME PIQUeras JuAN

Matrimonios en régimen de germania y relaciones intrafamiliares en Alicante durante el siglo XV

621 Aída PORTILLA GonzÁlez

El arte del buen morir en los testamentos medievales de la catedral de Sigüenza (siglos XIII-XV)

675 María Del Pilar RÁbade Obradó

Justas, fiestas y protagonismos: Alegrías y placeres en El Victorial de Gutierre Díaz de Games

699 TERESA SÁnchez ColladA

La dote matrimonial en el Derecho castellano de la Baja Edad Media. Los protocolos notariales del Archivo Histórico Provincial de Cuenca (1504-1507)

\section{Casto Manuel Solera Campos}

Pureza y continencia durante la Edad Media: la castidad conyugal en la Orden de Santiago (siglos XII-XVI)

\section{7 ÓsCAR VILLARROEL GONZÁlEZ}

Autoridad, legitimidad y honor en la diplomacia: los conflictos anglo-castellanos en los concilios del siglo XV

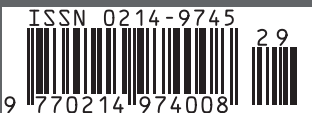




\section{9}

\section{ESPACIO,}

\section{TIEMPO}

Y FORMA

UกED

SERIE III HISTORIA MEDIEVAL

REVISTA DE LA FACULTAD DE GEOGRAFİA E HISTORIA

\section{Libros}

817 Álvarez Fernández, María y Beltrán SuÁrez, Soledad, Vivienda, gestión y mercado inmobiliarios en Oviedo en el tránsito de la Edad Media a la modernidad. El patrimonio urbano del cabildo catedralicio (RobERTO J. GONZÁlez ZALACAín)

821 BeCEIro PITA, Isabel (dir.), Poder, piedad y devoción. Castilla y su entorno, siglos XII-XV (ANA ECheVARría ARSUAGA)

825 García Fernández, Ernesto (Coord.), Laguardia y sus fueros. Estudios Históricos realizados en conmemoración del 850 aniversario de la concesión de la carta fundacional (ANA MARÍA RIVERA MEDINA)

829 García Fernández, Ernesto y Bonachía Hernando, Juan Antonio (eds.), Hacienda, mercado y poder al Norte de la Corona de Castilla en el tránsito del Medievo a la Modernidad (AnA María Rivera Medina)

843 Martín Prieto, Pablo, Las matemáticas en la Edad Media: una historia de las matemáticas en la Edad Media occidental (ANTONIO HERNANDO Esteban)

847 Miranda García, Fermín, Breve Historia de los Godos (Ana María JIMÉNEZ GARNICA)

851 Moreno Ollero, Antonio, Los dominios señoriales de la Casa de Velasco en la Baja Edad Media (DIEGo ARSUAGA LABORDE)

855 ORTEgo Rico, Pablo, Poder financiero y gestión tributaria en Castilla: Los agentes fiscales en Toledo y su reino (1429-1504) (Ana María Rivera Medina)

861 Solórzano Telechea, Jesús A. \& Arízaga bolumburu, Beatriz \& AgUiAR ANDRADE, Amélia (editores), Ser mujer en la ciudad medieval eUrOPEa (MARIANA ZAPATERO)

869 Solórzano Telechea, Jesús A. \& Arízaga bolumburu, Beatriz \& Sicking, Louis (eds.), Diplomacia y comercio en la Europa Atlántica Medieval (Roberto J. GonzÁlez ZaLACAín)

875 VÍtORES CASADO, Imanol \& GoICOLEA JULIÁN, Francisco Javier \& ANGULO Morales, Alberto \& Aragón RuAno, Álvaro (edición y estudios), Hacienda, fiscalidad y agentes económicos en la Cornisa Cantábrica y su entorno (1450-1550). Nuevos textos para su estudio (ENRIQUE CANTERA MONTENEGRO) 